\title{
Impact of awareness about hypertension on compliance to antihypertensive medication
}

\author{
Mansi Gupta ${ }^{1}$, D. D. Gupta ${ }^{2}$, Atal Sood ${ }^{3 *}$
}

${ }^{1}$ Department of Obstetrics and Gynaecology, ${ }^{2}$ Department of Pharmacology, Indira Gandhi Medical College, Shimla, Himachal Pradesh, India ${ }^{3}$ Department of Pharmacology, Dr. R P Govt. Medical College, Kangra, Tanda, Himachal Pradesh, India

Received: 09 December 2017 Accepted: 02 January 2018

\section{*Correspondence to:}

Dr. Atal Sood,

Email: atalsood7@gmail.com

Copyright: (C) the author(s), publisher and licensee Medip Academy. This is an openaccess article distributed under the terms of the Creative Commons Attribution NonCommercial License, which permits unrestricted noncommercial use, distribution, and reproduction in any medium, provided the original work is properly cited.

\begin{abstract}
Background: Hypertension, a common cardiovascular disorder accounts for 20$50 \%$ of all deaths. This risk can be greatly ameliorated by creating awareness about disease and its effective treatment alongside regular medical check-ups. Therapeutic failures result from patient non-compliance, manifested as intentional or unintentional errors in dosage or schedule, overuse or underuse of prescribed drugs and early termination of therapy. Adherence is helpful for management of hypertension and cost minimization. Non-adherence to the drug treatment is an important factor for uncontrolled hypertension and its complications.
\end{abstract}

Methods: Patients were interviewed individually after taking informed consent, using pretested, predesigned, self- administered and closed ended questionnaire both before and 4 weeks after creating awareness about hypertension and its complications. Compliance measured by self-reporting in which knowledge of the patient about number of antihypertensive drugs being used, formulations of drugs, frequency of administration, duration of taking the drugs and knowledge of complications due to uncontrolled and untreated hypertension were assigned 1 score each. Patient having score of at least 4 out of total 5 was considered compliant.

Results: No significant association of compliance with demographic and other variables like age, sex, marital status, economic status, education, urbanization, duration of treatment and drug procurement were noted. A significant increase in compliance in patients on antihypertensive medication was found 4 weeks after creating awareness about hypertension and its complication. A significant increase in compliance scores was also seen in non-compliant patients showing their shifting from non-compliance to compliance group. Overall compliance increased from $59.38 \%$ to $84.38 \%$. A percentage decrease from $58.82 \%$ to $25 \%$ in patients having uncontrolled hypertension was also observed after the awareness about hypertension.

Conclusions: Demographic variables, duration of hypertension and drug procurement have no significant effect on compliance to antihypertensive medication. There is persistence and improvement in compliance to antihypertensive medications after an education of the patients about hypertension and its complications.

Keywords: Antihypertensive medication, Compliance, Impact of awareness

\section{INTRODUCTION}

Hypertension (defined as: systolic B.P.>=130mm Hg; diastolic B.P. $>=80 \mathrm{~mm} \mathrm{Hg}$ ) is a condition in which arterial B.P. is chronically elevated..$^{1}$ It is the commonest cardio- vascular disorder, posing a major public health challenge, a major risk factor for cardiovascular mortality and accounts for $20-50 \%$ of all deaths. ${ }^{2}$ Raised blood pressure is responsible for $60 \%$ of strokes and $50 \%$ of coronary 
heart disease. ${ }^{3}$ Awareness about hypertension and effective therapy can reduce the risk. ${ }^{4}$

Overwhelming majority of the cases, underlying cause is unknown and such patients are labelled as idiopathic or essential hypertension. Because of escalating obesity and aging in developed and developing countries, the global burden of hypertension is rising and projected to effect 1.5 billion people all over the world, by year $2025 . .^{5}$ In India most recent data on hypertension showed a prevalence rate of 59.9 and 69.9 per 1000 in males and females, in urban populations and 35.5 and 35.9 per 1000 in males and females in rural population. ${ }^{2}$ Clinical cases of hypertension in developed countries represent just the tip of an iceberg. It has been found that $50 \%$ of the hypertensive patients are aware of the disease out of which $50 \%$ are being treated and only half of them are considered as adequately treated. The condition in developing countries is likely to be worse due to limited access to healthcare. ${ }^{2}$

Asymptomatic nature of the condition delays diagnosis. Effective treatment requires continuity of care by a good physician and regular medical check-ups, which are less in developing countries. ${ }^{5}$ Therapeutic failures result from patient non-compliance, manifested as intentional or unintentional errors in dosage or schedule, overuse or underuse of prescribed drugs and early termination of therapy. ${ }^{6}$ Strategies to reduce blood pressure by decreasing salt intake, increased potassium intake and pharmacotherapy will cause dramatic reduction in stroke, heart failure and heart attacks. Control of raised blood pressure is likely to result in considerable savings on health expenditure as hypertension is not only the biggest cause of death but also the $2^{\text {nd }}$ biggest cause of disability, after childhood malnutrition. ${ }^{3}$

Compliance or Adherence is defined as "the extent to which the patient follows medical instructions". Improvement in compliance to prescribed medications is necessary to avoid adverse outcomes. Non-compliance is not only due to patient factors, but care providers and healthcare system also plays a major role. ${ }^{8}$ Adherence is helpful for management of hypertension and cost minimization in cardiovascular diseases. ${ }^{9}$ Non-adherence to the drug treatment is an important factor for uncontrolled hypertension and incidence of complications due to hypertension. ${ }^{10}$ Simple strategies should be preferred in daily practice to improve adherence. Improvement in adherence provides maximum benefit of prescribed drugs. ${ }^{8}$

The present study was proposed to see the effect of creating awareness about hypertension, on compliance to antihypertensive medication in tertiary health care of this hilly area, as persistence and improvement in compliance is one of the important determinants in achieving favourable therapeutic outcomes.

Aims and objectives of the study were to study the impact on persistence and improvement of compliance to antihypertensive medication in essential hypertension, both before and after creating awareness about hypertension.

\section{METHODS}

After taking clearance from Institutional Ethics Committee (IEC) work commenced on this research project.

Patients attending Out Patient Clinic of Cardiology Department of IGMC, Shimla, a tertiary care teaching hospital of H.P. Duration of Study was 8 weeks.

Sample size includes, 40 patients were included in the study out of which 32 patients completed the study.

It was hospital based cross-sectional study.

\section{Study tool}

Participants were interviewed individually using pretested, pre-designed, self-administered, close ended questionnaire both before and after creating awareness about the disease.

\section{Inclusion criteria}

- Outdoor patients of both sexes above 18 years of age.

- Patients of isolated essential hypertension.

- Patients taking antihypertensive drugs for the last at least 3 months and able to take their medication themselves.

\section{Exclusion criteria}

- Taking drugs for any other chronic illness.

- Pregnancy and lactation.

- Secondary hypertension.

- Unwillingness to participate in the study.

\section{Measurement of blood pressure}

Patients were informed about the study in their own language and consent was obtained on the consent form (Annexure I). After 5 minutes of quiet rest two readings of B.P. in the seating position were taken with the help of sphygmomanometer and their mean was found. A cuff of adult size was used. The systolic B.P. was taken at Korotkoff phase I and diastolic at Korotkoff phase V. ${ }^{11}$ Patients with systolic B.P.>140 and diastolic B.P.>90 were labelled to have uncontrolled hypertension.

Compliance to antihypertensive drugs was measured on self-reporting by the patient, was considered convenient, economical and easily acceptable to the patients although a subjective method. Keeping in view various studies for measuring compliance on self reporting, a pre-tested, predesigned, self-administered, close ended questionnaire was prepared (Annexure-II). ${ }^{12-16}$ Considering a well- 
known fact that patients who are taking drugs regularly for the last 3 months or more and compliant must be well familiar with number of antihypertensive drugs being used, formulations of drugs, frequency of administration and duration of treatment. For the persistence and improvement of compliance, knowledge of hypertensive complications can be helpful and acts as good motivator for compliance to antihypertensive medications. For convenience a compliance scoring was used in which the knowledge of number of drugs being taken, formulations of drugs, frequency of administration of drugs, duration of treatment and knowledge of hypertensive complications were assigned one score each. A patient getting 4 out of total 5 scores was labelled as compliant and less than 4 was considered non-compliant. Non-compliant patients were interrogated for various barriers to compliance. Compliance was measured before and after 4 weeks of awareness about the disease. Patients were educated in their own language as language is as powerful tool as the medication prescribed. ${ }^{17}$ One to one verbal communication was done about the occurrence of various complications of untreated and uncontrolled hypertension, and about various barriers to compliance for its improvement and persistence. Patients having primary education and able to read and write a language were considered literate. Patients having per capita annual income less than Rs. 25000/were included in low income group.

\section{Statistical analysis}

Data were collected and analyzed using SPSS Version 16. The independent t-test was used to compare age. The Fisher exact test was used to compare categorical variables like sex, education, urbanization, marital status, and economic status, duration of hypertension and drug procurement in the two groups of compliant and noncompliant hypertension patients after creating awareness about hypertension. The paired t-test was used to compare the effect on compliance and non-compliance, before and after awareness about hypertension. $\mathrm{P}<=0.05$ was used as the cut-off level for statistical significance. $\mathrm{P}<=0.001$ was considered highly significant.

\section{RESULTS}

Of the total 40 subjects recruited in the study, only 32 attended the follow up clinic after 4 weeks of awareness about hypertension. The mean age of total subjects was 53 $(\mathrm{SD} \pm 12)$ years. Mean age for compliant subjects was $53.93( \pm 11.87)$ years and for non-compliant subjects was $48.80( \pm 9.21)$ years. Male to female ratio was $0.78: 1$ but for non-compliant $1.5: 1$. Only $68.75 \%$ of the total patients were literate while all non-compliant patients were found literate. Rural patients constituted $34.37 \%$ of the sample while $60 \%$ of the non-compliant patients were from rural area. Married patients amounted to be $87.50 \%$ of the total sample and the rest were unmarried divorced or widow. All unmarried were found compliant. Patients having low income Rs $<=25000 /$ - p.a. were $43.75 \%$ while $60 \%$ of the non-compliant patients were from high income group. The duration of hypertension was less than 5 yrs for $21(65.63 \%)$ patients and rest were having the disease for the last 5 or more yrs. $3(60 \%)$ of the non-compliant patients were having hypertension for the last 5 or more years. None of patient was found to have free drugs. 18(56.25\%) patients were getting expenditure for drugs reimbursed and rest were spending for drugs from their own pocket. $4(80.0 \%)$ of the non-compliant patients were having reimbursement of expenditure on drugs (Table 1).

All p values were based on Fisher exact test, except in age where the independent t-test was used.SD=Standard deviation. Values ore expressed as numbers (\%age), except in age in yrs. (Standard Deviation).

Table 1: Profile of compliant and non-compliant patients on antihypertensive drugs.

\begin{tabular}{|c|c|c|c|c|c|}
\hline \multicolumn{2}{|l|}{ Variables } & $\begin{array}{l}\text { Total } n=32 \\
(\%)\end{array}$ & $\begin{array}{l}\text { Compliant } \\
(\mathrm{n}=27)(\%)\end{array}$ & $\begin{array}{l}\text { Non-Compliant } \\
(\mathbf{n}=5)(\%)\end{array}$ & p Value \\
\hline \multicolumn{2}{|c|}{ Age in yrs Mean (SD) } & $53(12)$ & $53.93(11.87)$ & $48.80(9.21)$ & 0.369 \\
\hline \multirow{2}{*}{ Sex } & Male & $14(43.75 \%)$ & $11(40.74 \%)$ & $3(60 \%)$ & \multirow{2}{*}{0.631} \\
\hline & Female & $18(56.25 \%)$ & $16(59.26 \%)$ & $2(40 \%)$ & \\
\hline \multirow{2}{*}{ Urbanization } & Rural & $11(34.37 \%)$ & $8(29.63 \%)$ & $3(60 \%)$ & \multirow{2}{*}{0.310} \\
\hline & Urban & $21(65.63 \%)$ & $19(70.37 \%)$ & $2(40 \%)$ & \\
\hline \multirow{2}{*}{ Education } & Literate & $22(68.75 \%)$ & $17(62.96 \%)$ & $5(100 \%)$ & \multirow{2}{*}{0.155} \\
\hline & Illiterate & $10(31.25 \%)$ & $10(37.04 \%)$ & $0(0 \%)$ & \\
\hline \multirow{2}{*}{$\begin{array}{l}\text { Marital } \\
\text { status }\end{array}$} & Married & $28(87.5 \%)$ & $23(85.18 \%)$ & $5(100 \%)$ & \multirow{2}{*}{1.00} \\
\hline & Unmarried: (Single/ Divorced/ Widow) & $4(12.5 \%)$ & $4(14.82 \%)$ & $0(0 \%)$ & \\
\hline \multirow{2}{*}{$\begin{array}{l}\text { Economic } \\
\text { status }\end{array}$} & Low Income $(<25,000 /$ p.a. $)$ & $14(43.75 \%)$ & $12(44.44 \%)$ & $2(40 \%)$ & \multirow{2}{*}{1.00} \\
\hline & High Income (>25,000/p.a.) & $18(56.25 \%)$ & $15(55.56 \%)$ & $3(60 \%)$ & \\
\hline \multirow{2}{*}{$\begin{array}{l}\text { Duration of } \\
\text { hypertension }\end{array}$} & $<5 y r s$ & $21(65.63 \%)$ & $19(70.37)$ & $2(40 \%)$ & \multirow{2}{*}{0.310} \\
\hline & $>5 y r s$ & $11(34.37 \%)$ & $8(29.63)$ & $3(60 \%)$ & \\
\hline \multirow{3}{*}{$\begin{array}{l}\text { Drug } \\
\text { procurement }\end{array}$} & Free & $0(0 \%)$ & $0(0 \%)$ & $0(0 \%)$ & \multirow{3}{*}{0.355} \\
\hline & Reimbursed & $18(56.25 \%)$ & $14(51.85 \%)$ & $4(80 \%)$ & \\
\hline & Self-paid & $14(43.75 \%)$ & $13(48.15 \%)$ & $1(20 \%)$ & \\
\hline
\end{tabular}


There was no statistically significant difference in the mean age, sex distribution, literacy, urbanization, marital status, and economic status, duration of hypertension or drug procurement in compliant and non-compliant patients (Table 1). On the basis of compliance scores, a highly significant difference $(\mathrm{p}<0.001)$ was observed before and 4 weeks after awareness about hypertension in the study subjects. A significant increase in compliance score was observed in compliant patients $(n=19)$ and highly significant difference $(\mathrm{p}<0.001)$ in non-compliant patients $(n=13)$ before and after intervention of awareness about hypertension. A highly significant difference $(\mathrm{p}<0.001)$ in compliant patients $(\mathrm{n}=27)$ and significant difference $(\mathrm{p}<0.05)$ was also observed in non-complaint patients $(n=5)$ with awareness of the patients about hypertension (Table 2).

Table 2: Change in the compliance scores before and after creating awareness about hypertension between compliant and non-compliant patients.

\begin{tabular}{|llll|}
\hline $\begin{array}{l}\text { No. of } \\
\text { patients (n) }\end{array}$ & $\begin{array}{l}\text { Before } \\
\text { awareness }\end{array}$ & $\begin{array}{l}\text { 4 weeks after } \\
\text { awareness }\end{array}$ & p value \\
\hline $\begin{array}{l}\text { Total } \\
(\mathrm{n}=32)\end{array}$ & $\begin{array}{l}3.44 \\
(1.29)\end{array}$ & $4.41(0.84)$ & $<0.001^{* *}$ \\
\hline $\begin{array}{l}\text { Compliant } \\
(\mathrm{n}=19)\end{array}$ & $\begin{array}{l}4.37 \\
(0.50)\end{array}$ & $4.79(0.42)$ & $<0.002^{*}$ \\
\hline $\begin{array}{l}\text { Non- } \\
\text { Compliant } \\
(\mathrm{n}=13)\end{array}$ & $\begin{array}{l}2.08 \\
(0.76)\end{array}$ & $3.85(0.99)$ & $<0.001^{* *}$ \\
\hline $\begin{array}{l}\text { Compliant } \\
(\mathrm{n}=27)\end{array}$ & $\begin{array}{l}3.74 \\
(1.13)\end{array}$ & $4.70(0.47)$ & $<0.001^{* *}$ \\
\hline $\begin{array}{l}\text { Non- } \\
\text { Compliant } \\
(\mathrm{n}=5)\end{array}$ & $\begin{array}{l}1.80 \\
(0.84)\end{array}$ & $2.80(0.45)$ & $<0.050^{*}$ \\
\hline
\end{tabular}

Values are mean score (Standard Deviation). p Values were based on paired t-test. *Significant. ** Highly Significant.

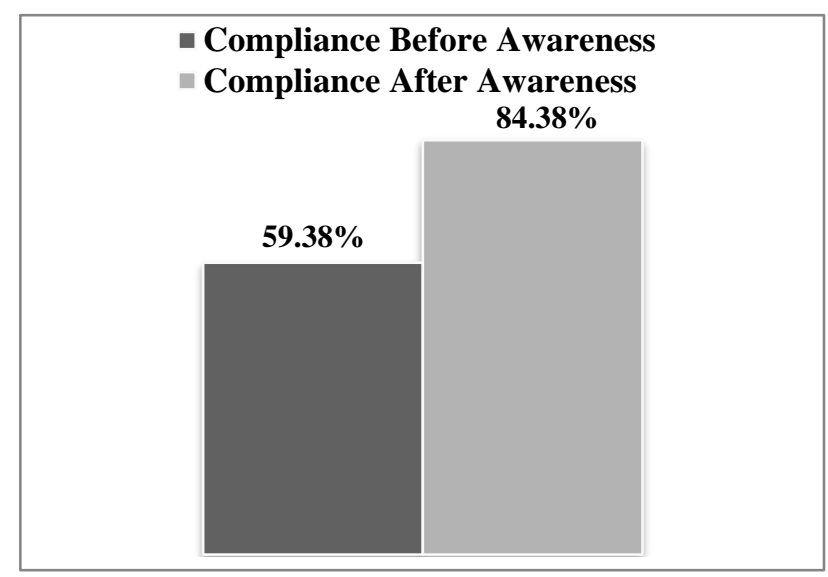

Figure 1: Compliance to antihypertensive drugs before and after awareness about hypertension.

The overall compliance rate increased from 19 (59.38\%) before awareness, to $27(84.38 \%) 4$ weeks after awareness about hypertension (Figure 1).
Uncontrolled hypertensive patients decreased from $17(58.82 \%)$ before awareness, to $8(25 \%) 4$ weeks after awareness about the disease (Figure 2).

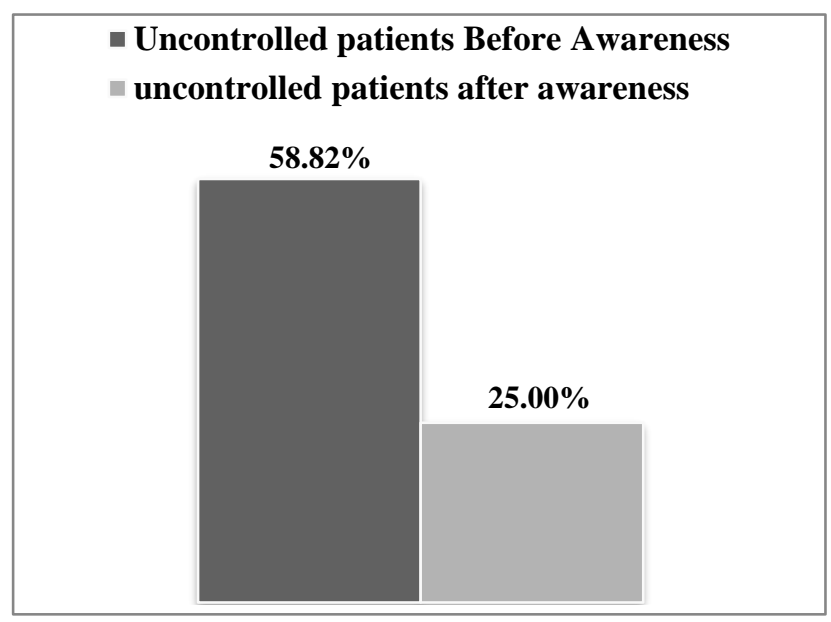

Figure 2: Uncontrolled hypertensive patients before and after awareness about hypertension.

\section{DISCUSSION}

The present study included 32 patients who were interviewed and made aware about hypertension, in cardiology out door clinic of a tertiary care government hospital. Our study investigated the impact of education about the occurrence of various complications of untreated and uncontrolled hypertension. Patients were educated about complications of hypertension and various barriers to compliance. Improvement and persistence of compliance to antihypertensive medication is said to play a significant role in favourable therapeutic outcome of treatment.

In our study no, significant correlation could be found for age, sex, education, urbanization, marital status, and economic status, duration of hypertension and drug procurement with compliance (Table 1) which is supported with other study also. ${ }^{18}$ There are different reports regarding these associations. One study shows poor adherence in younger age while the other study shows the association of high income and affordability with good compliance. ${ }^{19.20}$ Poor socioeconomic status and illiteracy have been found important factor for poor adherence. ${ }^{21}$ One study has shown more compliance in older patients, but there was no association with sex and marital status and also with education and economic status in another study. ${ }^{22,23}$ One study has shown positive association of age of 50 years or more and female sex with good compliance to antihypertensive medication. ${ }^{24}$ Studies shown no association of compliance with age and sex, but for literacy. ${ }^{25}$

The present study has shown significant increase in compliance scores of all study subjects as well as in case of compliant and non-compliant patients after educating the patients about hypertension (Table 2, Figure 1). A 
positive association of education of the patient about hypertension and improved compliance for antihypertensive medication has also been observed in other studies. ${ }^{19,20,21,26-29}$

One study however could not find significant effect of education of hypertensive patients through mailing education packets, on mildly uncontrolled hypertension, but significant improvement in patient knowledge, home monitoring and satisfaction was observed. ${ }^{30}$ In our study one to one verbal communication in the language of the patient probably proved more beneficial in improving compliance.

Percentages of patients suffering from uncontrolled hypertension have decreased after making the patients aware about hypertension and its complications if remained uncontrolled (Figure 2). Other studies have also shown the beneficial effect of improved and persistent compliance on uncontrolled hypertension or for adequate control of high blood pressure. ${ }^{13,21,27,31}$

In one study family based home health education by trained lay health workers along with education of general practitioners was found to have significant reduction in blood pressure among hypertensive patients. ${ }^{32}$ Less correlation of uncontrolled hypertensive patients with compliance was seen in one study in which $56 \%$ of uncontrolled patients were compliant and hence an improvement in the quality and efficacy of medical treatment was emphasized. ${ }^{25}$

Limitations of the study were to less number of patients in the study and self-reporting method to measure compliance in therapeutics is subjective and not much reliable in all situations.

Strength of the study of the study was planned to keep in view time and resources available and method was convenient and economical.

\section{CONCLUSION}

Based on the findings of the present study a significant and beneficial impact of awareness about hypertension and its complications, on compliance to antihypertensive medication is present. Persistence and improvement in compliance may help in achieving favourable therapeutic outcomes in patients on antihypertensive drugs.

\section{Funding: No funding sources}

Conflict of interest: None declared

Ethical approval: The study was approved by the Institutional Ethics Committee

\section{REFERENCES}

1. Greenland P, Peterson E. The New 2017 ACC/AHA Guidelines Up the pressure on Diagnosis and
Treatment of Hypertension. JAMA. 2017;318(21):2083-84.

2. Park K, Hypertension In: $23^{\text {rd }}$ Eds. Park's Textbook of Preventive and Social Medicine. India, Bhanot; 2015:372-377.

3. Feng J, MacGregor GA. Blood pressure is the most important cause of death and disability in the world. Eur Heart J. 2007;9(B):B23-8.

4. Galzerano D, Capogrosso C, Michele SD, Bobbio E, Paparello P, Gaudio. Do we need more than just powerful blood pressure reductions? New paradigms in end-organ protection Vascular Health and Risk Management. 2010;6:479-94.

5. Ronald GV, Norman MK, Systemic Hypertension In Peter L, Robert OB, Douglas LM, $8^{\text {th }}$ Eds. Braunwald's Heart Disease. Philadelphia, Saunders; 2008:1027-1048.

6. Iain LOB, Compliance In: Laurence LB, John SL, Keith LP, $11^{\text {th }}$ Eds. Goodman and Gilman's The Pharmacological Basis of Therapeutics. New York, Mc Graw Hill; 2006:1784-1786.

7. Defining adherence In: Adherence to Long term therapy Evidence for action. WHO; 2003:3-5.

8. Ho PM, Bryson CL, Rumsfeld JS. Medication Adherence: Its Importance in Cardiovascular Outcomes. Circulation. 2009;119:3028-35.

9. Esposti LD, Saragoni S, Batacchi P, Geppetti P, Buda S, Degli E. Antihypertensive therapy among newly treated patients: An analysis of adherence and cost of treatment over years Clinico Economics and Outcomes Research. 2010;2:113-20.

10. Feldman R, Bacher M, Campbell N, Drover A, Chockalingam A. Adherence to Pharmacologic Management of Hypertension. Canadian J Pub Health 1998;89(5):16-8.

11. Neil G, James S, Andrew B, Blood Pressure In: Graham D, Fiona N, Colin R, 12 ${ }^{\text {th }}$ Eds. Macleod's Clinical Examination. London, Churchill Livingstone; 2009:120-123.

12. Hawkshead J, Krousel W, Marie A, Techniques for Measuring Adherence in Hypertensive Patients in Outpatient Settings: Advantages and Limitations. Disease Management and Health Outcomes. 2007;15(2):109-18.

13. Gregoire JP, Guibert R, Mbault AA, Contandriopoulos PA. Medication Compliance in a Family Practice. Canadian Family Physician. 1992;38:2333-7.

14. Fairman K, Matheral B. Evaluating Medication Adherence: Which Measure Is Right for Your Program? J Managed Care Pharm. 2000;6(6):499-504.

15. Prado JC, Kupek E, Mion D. Validity of four indirect methods to measure adherence in primary care hypertensives. J Hum Hypertens. 2007;21:579-84.

16. Morisky DE, Ang A, Wood MK, Ward HJ. Predictive Validity of a Medication Adherence Measure in an Outpatient Setting. J Clin Hypertens. 2008;10(5):34854.

17. Steiner JF. Lingua Medica The Language of Medication-Taking. Ann Inter Med. 2000;132(11):926-30. 
18. Amal MA, Fatima AA, Maryam MK, Ali AA. Drug Compliance Among Hypertensive Patients; an Area Based Study. Eur J Gen Med. 2009;6(1):6-10.

19. Hashmi SK, Afridi MB, Abbas K, Sajwani RA, Saleheen D, Frossard PM. Factors Associated with Adherence to Anti-Hypertensive Treatment in Pakistan PLoS ONE. 2007;2(3):e280.

20. Kabir M, Iliyasu Z, Abubakar IS, Jibril M. Compliance to medication among hypertensive patients in Murtala Mohammed Specialist Hospital, Kano, Nigeria. Journal of Community Medicine and Primary Health Care. 2004;16(1):16-20.

21. Adherence to Long term therapy Evidence for action. WHO; 2003:107-114.

22. Hadi N, Gooran NR. Determinant Factors of Medication Compliance in Hypertensive Patients of Shiraz, Iran. Arch Iranian Med. 2004;7(4):292-6.

23. Hassan NB, Hasanah CI, Foong K, Naing L, Awang $\mathrm{R}$, Ismail $\mathrm{SB}$, et al. Identification of psychosocial factors of noncompliance in hypertensive patients. $\mathrm{J}$ Hum Hypertens. 2006;20:23-9.

24. Wong MCS, Jiang JY, Griffiths SM. Factors associated with antihypertensive drug compliance in 83884 Chinese patients: a cohort study JECH Online First, published on August 6, 2010.

25. Hungerbuhler P, Bovet P, Shamlaye C, Burnand B, Waeber B. Compliance with medication among outpatients with uncontrolled hypertension in the Seychelles. Bulletin of the World Health Organization. 1995;73(4):437-42.

26. Burge S, White D, Bajorek E, Bazaldua O, Trevino J, Albright T, et al. Correlates of Medication Knowledge and Adherence: Findings from the Residency
Research Network of South Texas. Fam Med. 2005;37(10):712-8.

27. Campbell NRC. The 2007 Canadian Hypertension Education Program recommendations: The scientific summary - an annual update Can J Cardiol. 2007;23:521-7.

28. Thrall G, Lip GYH, Lane D. Compliance with pharmacological therapy in hypertension: can we do better, and how? J Hum Hypertens. 2004;18:595-7.

29. Bovet P, Burnier M, Madeleine G, Waeber B, Paccaud F. Monitoring one-year compliance to antihypertension medication in the Seychelles. Bulletin of the World Health Organization. 2002;80(1):33-9.

30. Hunt JS, Siemienczuk J, Touchette D, Payne N. Impact of Educational Mailing on the Blood Pressure of Primary Care Patients with Mild Hypertension. J Gen Intern Med. 2004;19:925-30.

31. Krousel MA, Muntner P, Islam T, Morisky DE, Webber LS. Barriers to and Determinants of Medication Adherence in Hypertension Management: Perspective of the Cohort Study of Medication Adherence among Older Adults (CoSMO) Med Clin North Am. 2009;93(3):753-69.

32. Jafar TH, Hatcher J, Poulter N, Islam M, Hashmi S, Qadri Z, et al. Interventions to Promote Blood Pressure Control in a Developing Country Ann Intern Med. 2009;151:593-601.

Cite this article as: Gupta M, Gupta DD, Sood A. Impact of awareness about hypertension on compliance to antihypertensive medication. Int $\mathbf{J}$ Basic Clin Pharmacol 2018;7:244-51. 


\section{Annexure I}

\section{Informed Consent Form}

Study Title: Impact of awareness about hypertension on compliance to antihypertensive medication.

Case No.

I, Mr. /Mrs. aged son/ daughter/wife of resident of

have been fully explained as under:-

1. That I am participating in this study willingly and I can withdraw myself from this study at any time without assigning any reason. Because of this my treatment and legal rights will not be affected.

2. That I will give complete information to the investigator about my health and will not conceal anything in this regard.

3. That I have been well informed about the potential hazards of this study and have been given an adequate opportunity to ask any question in this regard.

4. That I give my consent for my participation in this study and assure for full cooperation about my medical examination and laboratory investigations etc. as and when desired by the investigator.

Place:

Dated:

Signature of Patient/Guardian

Place:

Signature of Investigator

Dated:

(Name and Address) 


\section{Annexure II}

Impact of awareness about hypertension on compliance to antihypertensive medication. Case No. Dated: Age... Sex.

Name \& Address

Contact no.

Occupation Education Per Capita Annual Income

Married/Unmarried/Divorced/Widow; Rural/Urban; Duration of Hypertension

Duration of taking antihypertensive medications ; Whether Symptomatic/Asymptomatic Drugs being procured: Free of Cost/Reimbursed/Self Paid ; No. of AntiHt. Drugs prescribed.

1. Is the patient taking the drugs? Regularly/Intermittently/ Not at all

2. If taking irregularly or not at all; reasons for taking drugs intermittently/ not at all: (a)Non availability (b) Forgetfulness (c) doesn't feel requirement (d) Lack of information (e)Adverse Effects (f) any others

3. Does the patient know the complications of hypertension? If yes; specify the complications;

4. Does he know about formulation, frequency \& duration of drugs prescribed last time?

\begin{tabular}{|l|l|l|l|}
\hline Name of Antihypertensive Drug & Formulation & Frequency & Duration \\
\hline & Yes / No & Yes / No & Yes / No \\
\hline & Yes / No & Yes / No & Yes / No \\
\hline & Yes / No & Yes / No & Yes / No \\
\hline & Yes / No & Yes / No & Yes / No \\
\hline
\end{tabular}

5. Does he think that long term use of antihypertensive drugs is harmful?

6. Does he think that disease is cured when blood pressure is controlled?

7. Does he know the importance of taking the antiHt. drugs even without symptoms?(Y/N)

8. Is he satisfied with his doctor?

( Yes / No )

9. Does he use some alternative medication for hypertension?

10. Does he feel that B.P. can be controlled even without drugs?

11. Does he attend the follow up regularly?

12. Does he know that antiHt. drugs are to be taken for indefinite period?

13. Does the patient monitor his BP periodically

BP; 1; $\mathrm{mmHg} 2$; $\mathrm{mmHg}$ 